
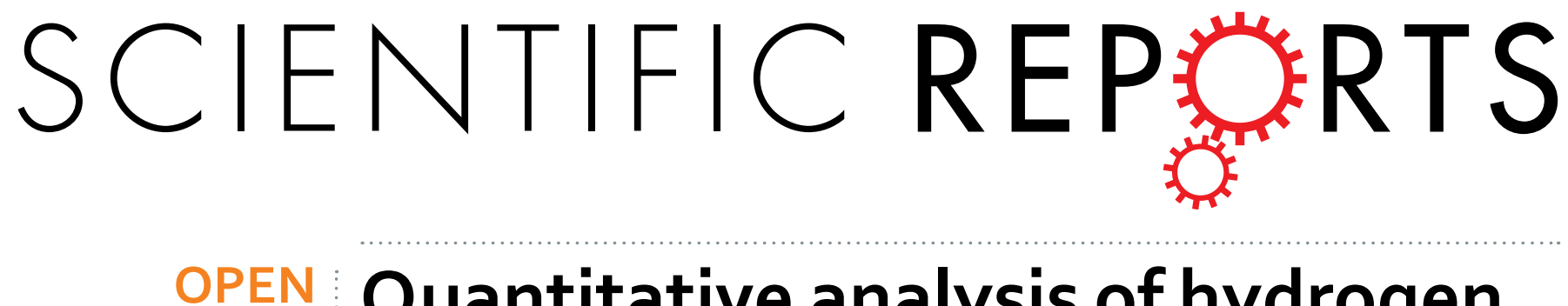

\title{
Quantitative analysis of hydrogen sites and occupancy in deep mantle hydrous wadsleyite using single
}

Received: 23 June 2016

Accepted: 14 September 2016

Published: 11 October 2016

\section{crystal neutron diffraction}

\author{
Narangoo Purevjav ${ }^{1}$, Takuo Okuchi ${ }^{1}$, Naotaka Tomioka ${ }^{1,2}$, Xiaoping Wang ${ }^{3} \&$ \\ Christina Hoffmann ${ }^{3}$
}

Evidence from seismological and mineralogical studies increasingly indicates that water from the oceans has been transported to the deep earth to form water-bearing dense mantle minerals. Wadsleyite $\left[\left(\mathrm{Mg}_{1} \mathrm{Fe}^{2+}\right)_{2} \mathrm{SiO}_{4}\right]$ has been identified as one of the most important host minerals incorporating this type of water, which is capable of storing the entire mass of the oceans as a hidden reservoir. To understand the effects of such water on the physical properties and chemical evolution of Earth's interior, it is essential to determine where in the crystal structure the hydration occurs and which chemical bonds are altered and weakened after hydration. Here, we conduct a neutron time-of-flight single-crystal Laue diffraction study on hydrous wadsleyite. Single crystals were grown under pressure to a size suitable for the experiment and with physical qualities representative of wet, deep mantle conditions. The results of this neutron single crystal diffraction study unambiguously demonstrate the method of hydrogen incorporation into the wadsleyite, which is qualitatively different from that of its denser polymorph, ringwoodite, in the wet mantle. The difference is a vital clue towards understanding why these dense mantle minerals show distinctly different softening behaviours after hydration.

A portion of water in Earth's oceans is continuously transported into the deep mantle as hydroxyl groups within dense hydrous minerals ${ }^{1-3}$. These minerals are carried by the downward motion of subducting oceanic plates, which are driven by plate tectonics. The mantle transition zone (MTZ) is between $410 \mathrm{~km}$ and $660 \mathrm{~km}$ depth and has been considered the primary destination for water transported from the oceans ${ }^{4-7}$. The MTZ consists mainly of wadsleyite and ringwoodite mineral phases, which are the two denser high-pressure polymorphs of olivine ${ }^{8}$. These three phases of $\left(\mathrm{Mg}, \mathrm{Fe}^{2+}\right)_{2} \mathrm{SiO}_{4}$ in the mantle are all nominally anhydrous; however wadsleyite and ringwoodite are capable of incorporating up to approximately $3 \mathrm{wt} . \%$ of $\mathrm{H}_{2} \mathrm{O}$ within their crystal structures ${ }^{3,7,9-13}$. To accept such an amount of water while maintaining dense crystal structures, hydrogen cations $\left(\mathrm{H}^{+}\right)$have been shown to substitute magnesium $\left(\mathrm{Mg}^{2+}\right)$ in both wadsleyite and ringwoodite, and also silicon $\left(\mathrm{Si}^{4+}\right)$ in the case of ringwoodite ${ }^{11,14-17}$.

Previous seismological studies proposed that some regions of the uppermost MTZ, at approximately $410 \mathrm{~km}$ depth, had anomalously lower velocities, which were interpreted as a result of the hydration reaction in a wet mantle environment where water transported from the surface became concentrated ${ }^{5,18}$. At this depth, olivine transforms into wadsleyite, and is then able to be hydrated. A more recent seismological study proposed that a large region of the lowermost MTZ, around $660 \mathrm{~km}$ depth, is so extensively hydrated that it is capable of inducing dehydration melting ${ }^{19}$.

On the other hand, it has commonly been reported by laboratory experiments and first principle calculations that the elastic constants of wadsleyite and ringwoodite monotonically decrease with increasing water concentration $^{15,20-22}$. This means that the crystals of wadsleyite and ringwoodite become more compressible after hydration, while their modified spinel and cubic spinel crystal structures, respectively, are preserved ${ }^{11,14}$. The structures of

${ }^{1}$ Institute for Planetary Materials, Okayama University, Misasa, Tottori 682-0193, Japan. ${ }^{2}$ Kochi Institute for Core Sample Research, Japan Agency for Marine-Earth Science and Technology, Nankoku, Kochi 783-8502, Japan. ${ }^{3}$ Chemical and Engineering Materials Division, Neutron Sciences Directorate, Oak Ridge National Laboratory, Oak Ridge, TN 37831, USA. Correspondence and requests for materials should be addressed to N.P. (email: pxec5a1c@s. okayama-u.ac.jp) 
both minerals are very similar because they share the cubic closest packing arrangement of oxygen atoms. As mentioned above, the regions comprised of hydrated wadsleyite or ringwoodite crystals with higher compressibility can be seismologically discriminated by their lower velocities, at least in the uppermost or lowermost MTZ, whereas water concentrations in these regions remain very difficult to estimate. This difficulty is partly because the degree of hydration-induced elastic constant reduction is strongly dependent on whether $\mathrm{Mg}^{2+}, \mathrm{Fe}^{2+}$ or $\mathrm{Si}^{4+}$ cations exchange with hydrogen during the process ${ }^{15,22}$. It has not yet been determined what fraction of these cations can be exchanged for hydrogen, especially in the case of hydrous wadsleyite. Additionally, the elastic constants of wadsleyite and ringwoodite have different sensitivities to the unit concentration of water, even though the two phases have very similar structures in dry conditions ${ }^{23}$. This difference implies that the two mineral phases may have distinctly different mechanisms for exchange between hydrogen and the other cations. In other words, the chemical bonding in hydrous wadsleyite and ringwoodite may be weakened at different positions in their crystal structures. To observe this difference, the hydrogen site and occupancy of wadsleyite was analysed in this study by neutron time-of-flight (TOF) single-crystal Laue diffraction ${ }^{24}$. As demonstrated in this study, this is by far the most powerful structural probe for detecting hydrogen in crystals. It has been successfully applied here for the first time to reveal the nature of chemically-bonded hydrogen in deep Earth minerals.

\section{Results and Discussion}

Hydrogen Site and Occupancy. Figure 1a shows the crystal structure of anhydrous wadsleyite in the orthorhombic space group Imma, which is briefly described here before discussing the hydrogen cations in this framework. Each $\mathrm{Mg}^{2+}$ is at one of three specific octahedral sites (M1 to M3), which is surrounded by six $\mathrm{O}^{2-}$.

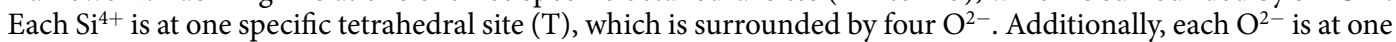
of four specific sites (O1 to O4), each of which possesses a different geometry of surrounding cations. Among them, $\mathrm{O} 1$ is particularly unique because it is not connected to $\mathrm{Si}^{4+}$, while all of the others $(\mathrm{O} 2, \mathrm{O} 3$ and $\mathrm{O} 4)$ have one or two neighbouring $\mathrm{Si}^{4+}$.

The structure parameters of wadsleyite obtained from single crystal neutron diffraction are shown in Tables 1 and 2. All atomic positions, including hydrogen, were refined using anisotropic Debye-Waller factors for our experimental hydrous wadsleyite using a high resolution dataset $(h k l)$ up to a minimum $d$-spacing $\left(d_{\text {min }}\right)$ of $0.30 \AA$. This resolution was significantly better than that of the previously obtained neutron powder diffraction pattern for a deuterated wadsleyite sample $\left(d_{\min }=0.96 \AA\right)^{16}$. Thus, using our single-crystal dataset, we provided a much more reliable site position and occupancy of hydrogen, as schematically illustrated in Fig. 1b. High-contrast and high-spatial resolution difference Fourier maps were also obtained to help visualise the position of hydrogen in the space-averaged structure (Fig. 1c-e).

The refined result of our dataset showed that there were four equivalent $\mathrm{H}^{+}$positions surrounding each of four equivalent $\mathrm{O} 1$ positions in the unit cell. While there was a total of 16 equivalent $\mathrm{H}^{+}$sites, it was found that these sites could not be simultaneously occupied. It was determined that to maintain local charge balance, the two $\mathrm{H}^{+}$ sites belonging to one empty M3 octahedron must be simultaneously occupied, where the octahedron consists of six oxygen atoms (two O1, two $\mathrm{O} 3$ and two $\mathrm{O} 4$ ). Each of these two $\mathrm{H}^{+}$was located along one of the two edges between the two O1-O4 pairs in that octahedron (Fig. 1b). The refined bond length of O1-H was 0.999(5) $\AA$ at $100 \mathrm{~K}$ and $0.987(6) \AA$ at $295 \mathrm{~K}$. The difference between these O-H distances is well below the 3 -sigma range and they are therefore nominally the same within their standard deviations. Compared with the deuterated wadsleyite, the positions of $\mathrm{O} 1$ and $\mathrm{H}$ are shifted slightly by $0.001 \AA$ and $0.007 \AA$, respectively, in the same direction along the $c$-axis ${ }^{16}$. Our observed $\mathrm{O}-\mathrm{H}$ bond length was $0.05 \AA$ shorter than that of the O-D reported in the deuterated wadsleyite. The hydrogen bond lengths $(\mathrm{O} 4 \ldots \mathrm{H})$ were $2.089(5) \AA$ and $2.105(6) \AA$ at $100 \mathrm{~K}$ and $295 \mathrm{~K}$, respectively, where the latter is slightly longer than the former. The hydrogen bonding was almost linear, with an O-H... angle of $171^{\circ}$ at both temperatures. The O4... H hydrogen bond was $0.06 \AA$ longer than that of O4...D in the deuterated wadsleyite, implying that the hydrogenated M3 octahedron had a slightly larger volume than that of the deuterated M3 octahedron.

The difference Fourier maps show the position of the largest negative scattering length density. The density was $-5.3 \mathrm{fm} / \AA^{3}$, which was far greater than the other negative residuals observed throughout all the datasets from $d_{\min }=0.30 \AA$ to $d_{\min }=0.60 \AA$ (see Fig. S1 for more detail on these residuals). Other than this $\mathrm{H}$ site, no other excess scattering length density distribution was observed. Therefore, this $\mathrm{H}$ site should be the only one possible place that incorporates protons in the hydrous wadsleyite crystal. To thoroughly establish this fact from a different viewpoint, we made additional efforts to refine the hydrogen occupancy. We compared the occupancy of the $\mathrm{H}^{+}$ site refined for several different datasets with the variable $d_{\text {min }}$. Figure 2 shows the charge of $\mathrm{H}^{+}$at the M3 site as a function of $d_{\text {min }}$, which was calculated from the refined occupancies deduced from the datasets of variable $d_{\text {min }}$. Where the $d_{\text {min }}$ was smaller than $0.325 \AA$, the observed charge of hydrogen became constant, whereas where the $d_{\text {min }}$ was larger than $0.35 \AA$, the charge depended on $d_{\text {min }}$. The amount of $\mathrm{H}^{+}$on the $\mathrm{M} 3$ site was converged to a partial occupancy of 0.105(2). The sum of the charge of $\mathrm{Mg}^{2+}$ and $\mathrm{H}^{+}$at $\mathrm{M} 3$ at $d_{\min } \leq 0.325 \AA$ was $2.000(4)$, which is equal with its stoichiometric value. Thus, the constant charge of $\mathrm{H}^{+}$with $d_{\min }$ at $0.30 \AA$ to $0.325 \AA$ at $100 \mathrm{~K}$ was proven to be reliable.

The total charge of $\mathrm{H}^{+}$in the bulk wadsleyite crystal can be estimated using the pre-established relationship between the water concentration (determined by infrared spectroscopy and secondary ion mass-spectroscopy), and the lattice constant ratio $b / a$ (determined by X-ray diffraction) ${ }^{25}$. The total $\mathrm{H}^{+}$charge estimated in this manner from the $b / a$ of our wadsleyite sample matched exactly the value deduced from the refined hydrogen occupancies found via neutron diffraction at $100 \mathrm{~K}$. Therefore, all hydrogen cations in the crystal (which collectively affect $b / a$ ) should have been fully concentrated into the M3 cavity. In other words, we confirmed that there are no other hydrogen sites. The maximum allowable concentration of $\mathrm{H}^{+}$in wadsleyite is thus constrained by its full capacity into $\mathrm{M} 3$, which corresponds to $3.33 \mathrm{wt} . \%$ of $\mathrm{H}_{2} \mathrm{O}$, as proposed by previous crystal chemical and secondary-ion mass spectroscopy analyses ${ }^{10,26}$. 
(a)

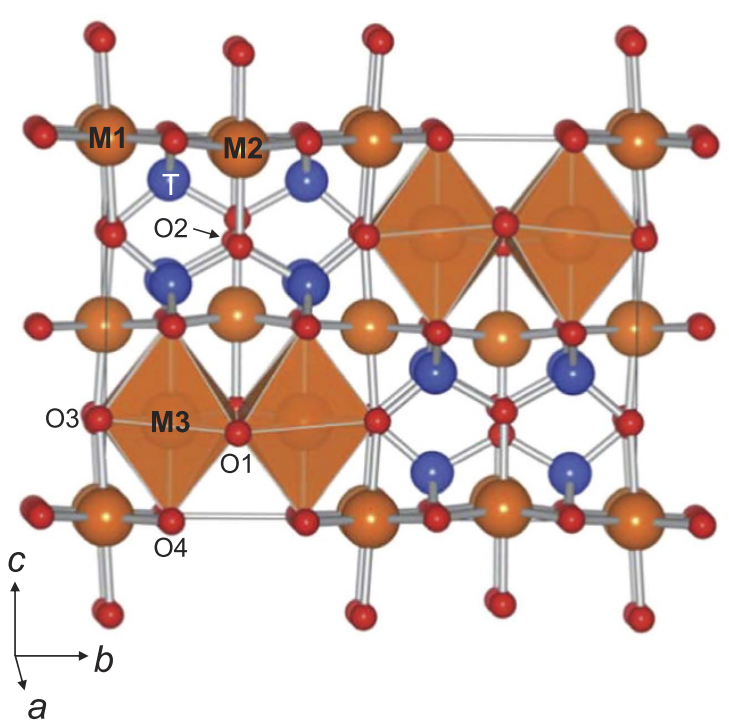

(c) $x=0.095$

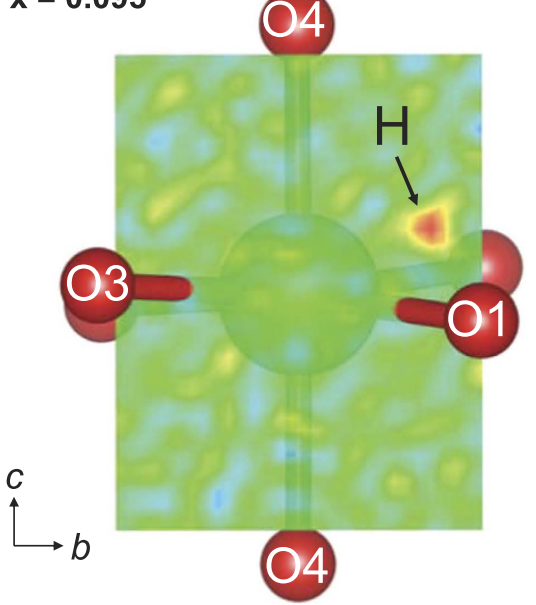

(e) $z=0.309$

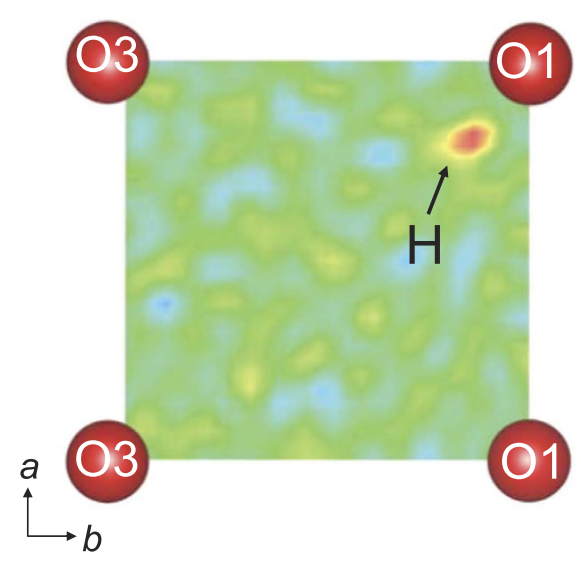

(b)

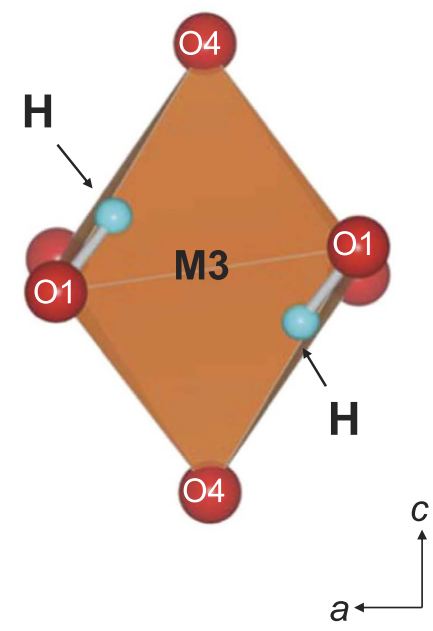

(d) $y=0.288$

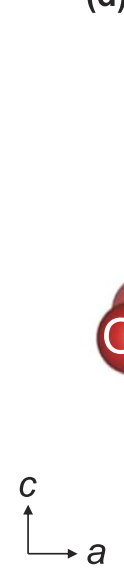

$z=0.191$

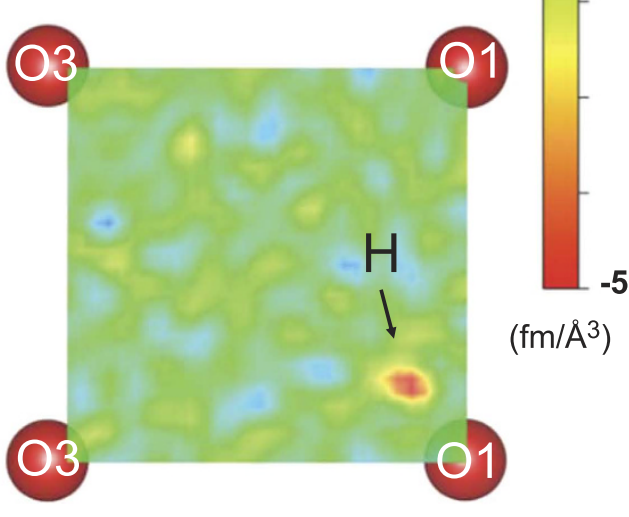

Figure 1. Framework of wadsleyite crystal structure and observed difference Fourier maps by neutron diffraction. These crystallographic illustrations were created using the software VESTA3 ${ }^{51}$. (a) Dry wadsleyite crystal structure with orthorhombic symmetry (Imma). (b) Position of $\mathrm{H}^{+}$in the local structure around the M3 octahedral site. The Fourier maps were generated from the difference of scattering length densities between those calculated from the dataset at $d_{\min }=0.30 \AA$ and those simulated for the dry wadsleyite structure. These maps show the slices at (c) (100) section at $x=0.095$, (d) (010) section at $y=0.288$ and (e) (001) section at $z=0.309$ and 0.191 , respectively. 


\begin{tabular}{|l|c|c|c|c|c|c|c|c|c|c|}
\hline Atom & $\boldsymbol{x} / \boldsymbol{a}$ & $\boldsymbol{y} / \boldsymbol{b}$ & $\boldsymbol{z} / \boldsymbol{c}$ & Occupancy & $\boldsymbol{U}_{11} \times \mathbf{1 0}^{\mathbf{2}^{*}}$ & $\boldsymbol{U}_{22} \times \mathbf{1 0}^{\mathbf{2}^{*}}$ & $\boldsymbol{U}_{33} \times \mathbf{1 0}^{\mathbf{2}^{*}}$ & $\boldsymbol{U}_{\mathbf{1 2}} \times \mathbf{1 0}^{\mathbf{2}^{*}}$ & $\boldsymbol{U}_{13} \times \mathbf{1 0}^{\mathbf{2}^{*}}$ & $\boldsymbol{U}_{23} \times \mathbf{1 0}^{\mathbf{2}^{*}}$ \\
\hline $\mathrm{Mg} 1$ & 0 & 0 & 0 & $1.001(2)$ & $0.764(12)$ & $0.451(8)$ & $0.942(10)$ & 0 & 0 & $0.146(7)$ \\
\hline $\mathrm{Mg} 2$ & 0 & $1 / 4$ & $0.97043(4)$ & $0.996(2)$ & $0.581(1)$ & $0.393(7)$ & $0.408(7)$ & 0 & 0 & 0 \\
\hline $\mathrm{Mg} 3$ & $1 / 4$ & $0.12444(2)$ & $1 / 4$ & $0.895(1)$ & $0.451(7)$ & $0.831(7)$ & $0.492(6)$ & 0 & $-0.018(6)$ & 0 \\
\hline $\mathrm{Si}$ & 0 & $0.12039(2)$ & $0.61624(3)$ & $0.999(1)$ & $0.375(7)$ & $0.354(6)$ & $0.368(6)$ & 0 & 0 & $-0.011(5)$ \\
\hline $\mathrm{O} 1$ & 0 & $1 / 4$ & $0.22166(4)$ & 1 & $0.416(9)$ & $0.641(8)$ & $0.708(8)$ & 0 & 0 & 0 \\
\hline $\mathrm{O} 2$ & 0 & $1 / 4$ & $0.71653(3)$ & 1 & $0.591(9)$ & $0.444(7)$ & $0.404(7)$ & 0 & 0 & 0 \\
\hline $\mathrm{O} 3$ & 0 & $0.98829(2)$ & $0.25585(3)$ & 1 & $0.591(7)$ & $0.547(5)$ & $0.463(5)$ & 0 & 0 & $0.049(4)$ \\
\hline $\mathrm{O} 4$ & $0.26055(3)$ & $0.12332(1)$ & $0.99392(2)$ & 1 & $0.452(4)$ & $0.495(3)$ & $0.509(4)$ & $-0.012(4)$ & $0.031(3)$ & $0.001(3)$ \\
\hline $\mathrm{H}$ & $0.0949(1)$ & $0.2882(4)$ & $0.3086(6)$ & $0.105(2)$ & $4.00(26)$ & $3.42(20)$ & $2.87(19)$ & $-0.92(17)$ & $-0.42(20)$ & $-0.79(15)$ \\
\hline
\end{tabular}

Table 1. Structure parameters at $100 \mathrm{~K} .{ }^{*} U_{i j}$ is anisotropic Debye-Waller factors.

\begin{tabular}{|c|c|c|c|c|c|c|c|c|c|c|}
\hline Atom & $x / a$ & $y / b$ & $z / c$ & Occupancy & $U_{11} \times 10^{2^{2}}$ & $U_{22} \times 10^{2^{*}}$ & $U_{33} \times 10^{2^{*}}$ & $U_{12} \times 10^{2^{2}}$ & $U_{13} \times 10^{2^{*}}$ & $U_{23} \times 10^{2 *}$ \\
\hline Mg1 & 0 & 0 & 0 & $1.000(2)$ & $0.983(15)$ & $0.598(10)$ & $1.186(13)$ & 0 & 0 & $0.111(8)$ \\
\hline Mg2 & 0 & $1 / 4$ & $97011(5)$ & $0.997(2)$ & $0.802(13)$ & $0.540(9)$ & $0.612(10)$ & 0 & 0 & 0 \\
\hline Mg3 & $1 / 4$ & $0.12437(3)$ & $1 / 4$ & $0.898(1)$ & $0.598(9)$ & $1.030(8)$ & $0.724(8)$ & 0 & $-0.058(7)$ & 0 \\
\hline Sil & 0 & $0.12042(3)$ & $0.61613(4)$ & $1.001(2)$ & $0.503(8)$ & $0.478(7)$ & $0.494(8)$ & 0 & 0 & $-0.015(6)$ \\
\hline O1 & 0 & $1 / 4$ & $0.22140(5)$ & 1 & $0.538(11)$ & $0.807(9)$ & $0.900(11)$ & 0 & 0 & 0 \\
\hline $\mathrm{O} 2$ & 0 & $1 / 4$ & $0.71627(4)$ & 1 & $0.824(11)$ & $0.550(8)$ & $0.548(9)$ & 0 & 0 & 0 \\
\hline O3 & 0 & $0.98818(2)$ & $0.25595(3)$ & 1 & $0.742(8)$ & $0.712(6)$ & $0.627(7)$ & 0 & 0 & $0.093(5)$ \\
\hline O4 & $0.26076(3)$ & $0.12330(2)$ & $0.99382(2)$ & 1 & $0.583(5)$ & $0.653(4)$ & $0.699(5)$ & $-0.014(5)$ & $0.067(4)$ & $-0.003(3)$ \\
\hline $\mathrm{H}$ & $0.0933(2)$ & $0.2873(5)$ & $0.3076(8)$ & $0.081(2)$ & $3.42(32)$ & $2.56(20)$ & $2.04(23)$ & $-0.73(19)$ & $-0.13(22)$ & $-0.58(18)$ \\
\hline
\end{tabular}

Table 2. Structure parameters at $295 \mathrm{~K} .{ }^{*} U_{\mathrm{ij}}$ is anisotropic Debye-Waller factors.

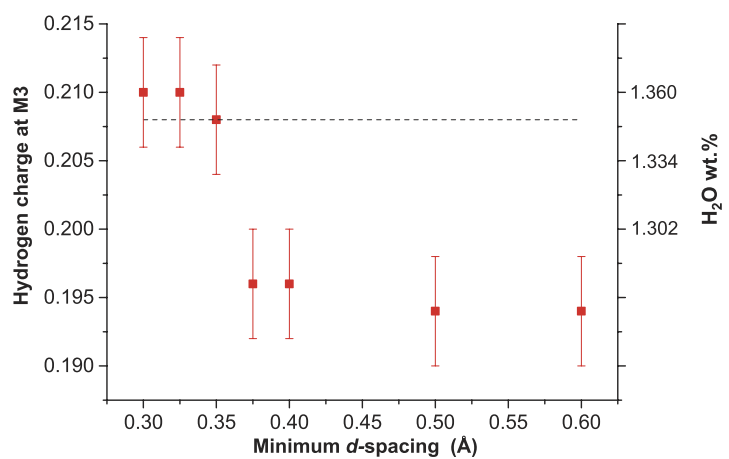

Figure 2. Observed total charge of hydrogen at the M3 octahedral site as a function of $\boldsymbol{d}_{\text {min }}$. The dashed line is the charge of $\mathrm{H}^{+}$independently estimated from the lattice constant ratio $b / a^{25}$.

A recent study evaluating the chemical environment of $\mathrm{H}^{+}$in wadsleyite by nuclear magnetic resonance spectroscopy reported that some minor $\mathrm{H}^{+}$was bonded with oxygen $\mathrm{O} 3$ that belonged to $\mathrm{Si}^{4+27}$. This finding is different from our results and may have resulted from different synthesis conditions. While their wadsleyite samples were synthesised in a solid state condition at relatively low temperatures from $1100^{\circ} \mathrm{C}$ to $1200^{\circ} \mathrm{C}$, our crystals were grown in a partially-molten silicate melt at $1400^{\circ} \mathrm{C}$ (see Methods for details). The strain environment may have also been different, as our single crystal was grown under a hydrostatic condition in the melt, while the growth conditions of their powder samples are unknown. Accordingly, it is necessary to consider the effect of non-hydrostatic growth environments on the oxygen species, which were found to be bonding with a minor fraction of the hydrogen. Additionally, hydrogen may also couple with $\mathrm{Fe}^{3+}$ to exchange for $\mathrm{Si}^{4+}$ at $\mathrm{T}$ sites ${ }^{28-30}$. Further neutron diffraction study is required to observe this cation-coupled substitution mechanism in iron-bearing hydrous wadsleyite crystals at elevated oxygen-fugacity conditions.

The total charge balances including all cations of the structure are summarized in Fig. 3, which shows all cation species refined at all sites for the dataset at $d_{\text {min }}=0.30 \AA$ obtained at $100 \mathrm{~K}$. The charges of $\mathrm{Mg}^{2+}$ and $\mathrm{Si}^{4+}$ at M1, M2 and T sites were all equal with their stoichiometric values within the standard deviation of the refinement. The $\mathrm{Mg}^{2+}$ charge at M3 was significantly smaller than the stoichiometric value, whereas the sum of $\mathrm{Mg}^{2+}$ and $\mathrm{H}^{+}$charges at M3 was equal to the stoichiometric value. The calculated $\mathrm{H}_{2} \mathrm{O}$ concentration from the $\mathrm{H}^{+}$ charge at M3 was 1.36 wt.\%. Recently, we showed that a powder neutron diffraction study is useful to quantitatively constrain $\mathrm{D}_{2} \mathrm{O}$ concentration in a dense hydrous magnesium silicate ${ }^{31}$. The present study further expanded 


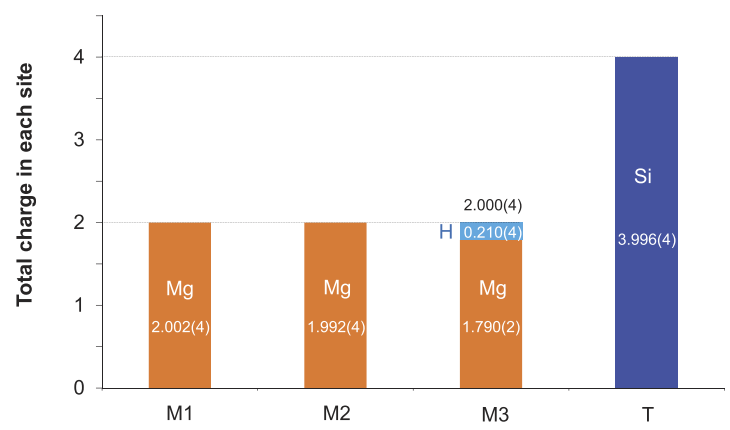

Figure 3. Observed charge number of all cations at each site of the hydrous wadsleyite, calculated from the refined occupancies. These occupancies were not constrained during the structure refinement. The dashed line shows the stoichiometric charge values of each site.

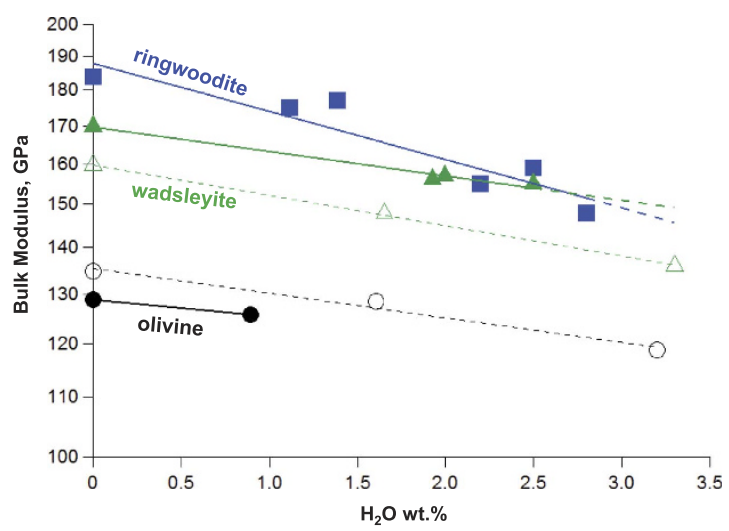

Figure 4. Experimental and theoretical results showing decreasing bulk moduli as a function of increasing water concentration. Triangles, squares and circles represent wadsleyite, ringwoodite and olivine results, respectively. All filled symbols represent experimental results ${ }^{20-21,23,33-41}$. The open triangles and open circles represent density functional theory results for olivine and wadsleyite, respectively, where all hydrogen cations were positioned at $\mathrm{M}$ sites by exchanging for $\mathrm{Mg}^{2+15,42}$. The vertical axis is shown in the log scale. The slopes of decreasing bulk moduli of wadsleyite and olivine are almost comparable, while that of ringwoodite is steeper than these two. See discussion in the text.

the unique potential of the neutron diffraction method for a quantitative analysis of $\mathrm{H}_{2} \mathrm{O}$ concentrations of minerals, even at such low concentrations as those found in nominally anhydrous high-pressure minerals.

Hydrous Wadsleyite and Hydrous Ringwoodite. Seismic velocity in the deep mantle shows major discontinuities at 410,520 and $660 \mathrm{~km}$, which are ascribed to the occurrence of three phase transformations, including those from olivine to wadsleyite, from wadsleyite to ringwoodite and from ringwoodite to bridgmanite $\left[\left(\mathrm{Mg}, \mathrm{Fe}^{2+}\right) \mathrm{SiO}_{3}\right]$ and magnesiowüstite $\left[\left(\mathrm{Mg}, \mathrm{Fe}^{2+}\right) \mathrm{O}\right]$, respectively ${ }^{8,32}$. Wadsleyite and ringwoodite in the MTZ are unique with respect to their larger water capacity compared to other nominally anhydrous minerals outside of the MTZ. The lower MTZ is considered to be extensively hydrated, at least in certain regions, as demonstrated by a recent discovery of natural hydrous ringwoodite ${ }^{7}$. Assuming that this water has been transported from the oceans, it would have passed through the upper MTZ and hydrated any wadsleyite in its path.

As an example of the systematic differences in the properties of wadsleyite and ringwoodite induced after hydration, we summarised the decreasing trends of their bulk moduli as a function of water concentration (Fig. 4). All of these data points were taken from previous experimental and theoretical studies on Fe-free and Fe-bearing hydrous wadsleyite and ringwoodite ${ }^{15,20-21,23,33-40}$. For reference, we also included experimental and theoretical results for hydrous olivine, which is expected to have a similar hydration mechanism with that of wadsleyite $^{41,42}$. It is clear that the slope of decreasing bulk moduli exhibited by ringwoodite is relatively steeper than those of wadsleyite and olivine. Therefore, despite wadsleyite and ringwoodite having very similar crystal structures in their dry forms, they are expected to have significantly different hydration mechanisms. In this study, we have clarified that $\mathrm{H}^{+}$in wadsleyite is exclusively present at one of its octahedral sites (M3), while we previously demonstrated that $\mathrm{H}^{+}$in ringwoodite should be present at both octahedral and tetrahedral sites ${ }^{17}$. This contrast in hydration mechanisms may be the primary reason that a larger reduction of bulk modulus is seen for ringwoodite than for wadsleyite (the two bulk moduli have a $15 \mathrm{GPa}$ difference at zero $\mathrm{H}_{2} \mathrm{O}$ concentration but become indistinguishable at greater than $2.0 \mathrm{wt} . \% \mathrm{H}_{2} \mathrm{O}$ ). The larger effect of hydration on ringwoodite than on wadsleyite was supported by a previous first principle study, where it was predicted that hydration of the tetrahedral sites is much more effective at reducing elastic properties than hydration of the octahedral sites ${ }^{22}$. Future detailed 
crystal structure analyses of hydrated mantle minerals would enable more precise predictions of their physical properties, which would lead to a more complete interpretation of the seismic structure of the deep Earth interior.

\section{Methods}

Sample Preparation. Iron-free single-crystals of hydrous wadsleyite were synthesised by the slow-cooling method using a scaled-up Kawai-type cell ${ }^{43}$. We prepared a mixture of $\mathrm{MgO}, \mathrm{Mg}(\mathrm{OH})_{2}$ and $\mathrm{SiO}_{2}$ powders involving 15 wt. $\%$ of $\mathrm{H}_{2} \mathrm{O}$. About $45 \mathrm{mg}$ of the mixture were sealed into an Au capsule with a $4 \mathrm{~mm}$ outer diameter, compressed to $17 \mathrm{GPa}$ pressure and heated to $1380 \pm 20^{\circ} \mathrm{C}$ for 6 hours, where crystals were grown and homogenised in a silicate partial melt. Over 20 product crystals, all of which had identical chemical compositions ${ }^{43}$, were simultaneously quenched and recovered to ambient conditions. Some of the largest crystals were analysed using microfocus X-ray diffraction (Rigaku RINT RAPID II) for phase identification and several crystals were further analysed by X-ray precession photography for evaluation of crystal quality. A portion of the other crystals were polished and measured by a scanning electron microscope (JEOL JSM-7001F) to confirm their chemical homogeneity. A single crystal was analysed by Fourier-transform infrared (FTIR) spectroscopy (Jasco FTIR-6200) to confirm its homogeneous hydrogen distribution (Fig. S2). Other crystals were ground into fine powder and measured by powder X-ray diffraction (Rigaku SmartLab) at $295 \mathrm{~K}$ to precisely refine the lattice constants and the unit cell volume, which were $a=5.6865(4) \AA, b=11.515(2) \AA, c=8.2545(7) \AA, V=540.52(5) \AA^{3}$ and $\beta=89.985(13)^{\circ}$. Because the structure of hydrous wadsleyite may show either monoclinic or orthorhombic symmetry ${ }^{44,45}$, the $\beta$ angle was determined to define the symmetry of the atomic positions. The $\beta$ angle was almost within one sigma range of $90^{\circ}$, indicating orthorhombic symmetry. We verified that forbidden reflections for the orthorhombic space group Imma were not observed in the powder X-ray pattern, providing further support for the orthorhombic symmetry. The refinement of a well-calibrated powder X-ray pattern is the most accurate method for obtaining these constants, even if high-quality neutron diffraction data are available ${ }^{17,31}$. Using the results of precession photography, we selected the crystal with the highest crystallinity for neutron diffraction, measuring $800 \mu \mathrm{m}$ in its longest dimension and completely free from twinning, inclusion and diffuse scattering (Fig. S3).

Single-Crystal Neutron Diffraction. The diffraction experiment was conducted on the neutron TOF single-crystal Laue diffractometer TOPAZ installed at Spallation Neutron Source (SNS), Oak Ridge National Laboratory (ORNL), USA. This state-of-the-art diffractometer was used successfully to obtain a dataset with a superior spatial resolution, even for the tiny crystal sample volume of this study, which was one order of magnitude smaller than that of crystals used previously for single-crystal neutron diffraction ${ }^{46,47}$. The crystal was mounted on a $500 \mu \mathrm{m}$-diameter pin-base polyimide tube using a small amount of epoxy resin under a microscope setup. Each dataset (at $100 \mathrm{~K}$ and $295 \mathrm{~K}$ temperatures) was obtained over a duration of two or three days.

We again verified that neutron intensities of the forbidden reflections for the space group Imma were all within the background level. The neutron datasets were then analysed using the GSAS program ${ }^{48}$. The initial non-hydrogen atomic coordinates were taken from a previous powder neutron diffraction study ${ }^{16}$. The initial hydrogen positions were taken from the results of difference Fourier synthesis. The structure refinements were carried out with a secondary type I Lorentzian spread extinction model ${ }^{49,50}$, where the $R w(\mathrm{~F})$ for the $100 \mathrm{~K}$ dataset was $5.1 \%$ before and $4.4 \%$ after positioning of hydrogen atoms. Thus the full refinement was successfully converged at $R w(\mathrm{~F})=4.4 \%$ and $R(\mathrm{~F})=5.8 \%$ for the $100 \mathrm{~K}$ dataset and at $R w(\mathrm{~F})=4.4 \%$ and $R(\mathrm{~F})=6.2 \%$ for the $295 \mathrm{~K}$ dataset. The Debye-Waller factors of atoms at $100 \mathrm{~K}$ were substantially smaller than those at $295 \mathrm{~K}$. This is because thermal vibration of these atoms decreased with decreasing temperature, resulting in a more concentrated scattering length density distribution in space. In the case of hydrogen atoms, such concentration proved to be significant enough to improve the accuracy of the observed scattering length density and site occupancy of hydrogen.

\section{References}

1. Peacock, S. M. Fluid processes in subduction zones. Science 248, 329-337 (1990).

2. Thompson, A. B. Water in the Earth's upper mantle. Nature 358, 295-302 (1992).

3. Ohtani, E., Litasov, K., Hosoya, T., Kubo, T. \& Kondo, T. Water transport into the deep mantle and formation of a hydrous transition zone. Phys. Earth Planet. Inter. 143, 255-269 (2004).

4. Bercovici, D. \& Karato, S. Whole-mantle convection and the transition-zone water filter. Nature 425, 39-44 (2003).

5. Song, T. R. A., Helmberger, D. V. \& Grand, S. P. Low-velocity zone atop the 410-km seismic discontinuity in the northwestern United States. Nature 427, 530-533 (2004).

6. Khan, A. \& Shankland, T. J. A geophysical perspective on mantle water content and melting: Inverting electromagnetic sounding data using laboratory-based electrical conductivity profiles. Earth Planet. Sci. Lett. 317, 27-43 (2012).

7. Pearson, D. G. et al. Hydrous mantle transition zone indicated by ringwoodite included within diamond. Nature 507, 221-224 (2014).

8. Katsura, T. \& Ito, E. The System $\mathrm{Mg}_{2} \mathrm{SiO}_{4}-\mathrm{Fe}_{2} \mathrm{SiO}_{4}$ at high-pressures and temperatures-precise determination of stabilities of olivine, modified spinel, and spinel. J. Geophys. Res. 94, 15663-15670 (1989).

9. Smyth, J. R. $\beta-\mathrm{Mg}_{2} \mathrm{SiO}_{4}$; a potential host for water in the mantle. Am. Mineral. 72, 1051-1055 (1987).

10. Inoue, T., Yurimoto, H. \& Kudoh, Y. Hydrous Modified Spinel, $\mathrm{Mg}_{1.75} \mathrm{SiH}_{0.5} \mathrm{O}_{4}-\mathrm{A}$ new water reservoir in the mantle transition region. Geophys. Res. Lett. 22, 117-120 (1995).

11. Kudoh, Y., Inoue, T. \& Arashi, H. Structure and crystal chemistry of hydrous wadsleyite, $\mathrm{Mg}_{1.75} \mathrm{SiH}_{0.5} \mathrm{O}_{4}$ : Possible hydrous magnesium silicate in the mantle transition zone. Phys. Chem. Miner. 23, 461-469 (1996).

12. Kohlstedt, D. L., Keppler, H. \& Rubie, D. C. Solubility of water in the $\alpha, \beta$ and $\gamma$ phases of $(\mathrm{Mg}, \mathrm{Fe})_{2} \mathrm{SiO}_{4}$. Contrib. Mineral. Petrol. 123, 345-357 (1996)

13. Thomas, S.-M. et al. Quantification of water in hydrous ringwoodite. Frontiers in Earth Science 2, 38 (2015).

14. Kudoh, Y., Kuribayashi, T., Mizobata, H. \& Ohtani, E. Structure and cation disorder of hydrous ringwoodite, $\gamma-\mathrm{Mg}_{1.89} \mathrm{Si}_{0.98} \mathrm{H}_{0.30} \mathrm{O}_{4}$. Phys. Chem. Miner. 27, 474-479 (2000).

15. Tsuchiya, J. \& Tsuchiya, T. First principles investigation of the structural and elastic properties of hydrous wadsleyite under pressure. J. Geophys. Res. 114, B02206 (2009).

16. Sano-Furukawa, A., Kuribayashi, T., Komatsu, K., Yagi, T. \& Ohtani, E. Investigation of hydrogen sites of wadsleyite: A neutron diffraction study. Phys. Earth Planet. Inter. 189, 56-62 (2011). 
17. Purevjav, N., Okuchi, T., Tomioka, N., Abe, J. \& Harjo, S. Hydrogen site analysis of hydrous ringwoodite in mantle transition zone by pulsed neutron diffraction. Geophys. Res. Lett. 41, 6718-6724 (2014).

18. Van der Meijde, M., Marone, F., Giardini, D. \& van der Lee, S. Seismic evidence for water deep in earth's upper mantle. Science 300, 1556-1558 (2003).

19. Schmandt, B., Jacobsen, S. D., Becker, T. W., Liu, Z. X. \& Dueker, K. G. Dehydration melting at the top of the lower mantle. Science 344, 1265-1268 (2014).

20. Mao, Z. et al. Elasticity of hydrous wadsleyite to $12 \mathrm{GPa}$ : Implications for Earth's transition zone. Geophys. Res. Lett. 35, L21305 (2008).

21. Inoue, T., Weidner, D. J., Northrup, P. A. \& Parise, J. B. Elastic properties of hydrous ringwoodite ( $\gamma$-phase) in $\mathrm{Mg}_{2} \mathrm{SiO}_{4}$. Earth Planet. Sci. Lett. 160, 107-113 (1998).

22. Panero, W. R. First principles determination of the structure and elasticity of hydrous ringwoodite. J. Geophys. Res. 115, B03203 (2010).

23. Mao, Z. et al. Sound velocities of hydrous ringwoodite to $16 \mathrm{GPa}$ and 673 K. Earth Planet. Sci. Lett. 331, 112-119 (2012).

24. Schultz, A. J. et al. Integration of neutron time-of-flight single-crystal Bragg peaks in reciprocal space. J. Appl. Cryst. 47, 915-921 (2014).

25. Jacobsen, S. D., Demouchy, S., Frost, D. J., Ballaran, T. B. \& Kung, J. A systematic study of OH in hydrous wadsleyite from polarized FTIR spectroscopy and single-crystal X-ray diffraction: Oxygen sites for hydrogen storage in Earth's interior. Am. Mineral. 90, 61-70 (2005).

26. Smyth, J. R. A Crystallographic model for hydrous wadsleyite $\left(\gamma-\mathrm{Mg}_{2} \mathrm{SiO}_{4}\right)$-an ocean in the Earth's interior. Am. Mineral. 79, 1021-1024 (1994).

27. Griffin, J. M., Berry, A. J., Frost, D. J., Wimperis, S. \& Ashbrook, S. E. Water in the Earth's mantle: a solid-state NMR study of hydrous wadsleyite. Chem. Sci. 4, 1523-1538 (2013).

28. Bolfan-Casanova, N. et al. Ferric iron and water incorporation in wadsleyite under hydrous and oxidizing conditions: A XANES, Mossbauer, and SIMS study. Am. Mineral. 97, 1483-1493 (2012).

29. Smyth, J. R., Bolfan-Casanova, N., Avignant, D., El-Ghozzi, M. \& Hirner, S. M. Tetrahedral ferric iron in oxidized hydrous wadsleyite. Am. Mineral. 99, 458-466 (2014).

30. Mrosko, M. et al. Water, iron, redox environment: effects on the wadsleyite-ringwoodite phase transition. Contrib. Mineral. Petrol. 170, $9(2015)$.

31. Tomioka, N., Okuchi, T., Purevjav, N., Abe, J. \& Harjo, S. Hydrogen sites in the dense hydrous magnesian silicate phase E: A pulsedneutron powder diffraction study, Phys. Chem. Miner. 43, 267-275 (2016).

32. Ito, E. \& Takahashi, E. Postspinel transformations in the system $\mathrm{Mg}_{2} \mathrm{SiO}_{4}-\mathrm{Fe}_{2} \mathrm{SiO}_{4}$ and Some Geophysical Implications. J. Geophys. Res. 94, 10637-10646 (1989).

33. Zha, C. S. et al. Single-crystal elasticity of $\beta-\mathrm{Mg}_{2} \mathrm{SiO}_{4}$ to the pressure of the $410 \mathrm{~km}$ seismic discontinuity in the Earth's mantle. Earth Planet. Sci. Lett. 147, E9-E15 (1997)

34. Yusa, H. \& Inoue, T. Compressibility of hydrous wadsleyite ( $\beta$-phase) in $\mathrm{Mg}_{2} \mathrm{SiO}_{4}$ by high pressure X-ray diffraction. Geophys. Res. Lett. 24, 1831-1834 (1997).

35. Hazen, R. M. Comparative compressibilities of silicate spinels - Anomalous behavior of (Mg,Fe) $)_{2} \mathrm{SiO}_{4}$. Science 259, 206-209 (1993).

36. Yusa, H., Inoue, T. \& Ohishi, Y. Isothermal compressibility of hydrous ringwoodite and its relation to the mantle discontinuities. Geophys. Res. Lett. 27, 413-416 (2000).

37. Mao, Z. et al. Effect of hydration on the single-crystal elasticity of Fe-bearing wadsleyite to $12 \mathrm{GPa}$. Am. Mineral. 96, 1606-1612 (2011).

38. Sinogeikin, S. V., Katsura, T. \& Bass, J. D. Sound velocities and elastic properties of Fe-bearing wadsleyite and ringwoodite. J. Geophys. Res. 103, 20819-20825 (1998).

39. Ye, Y. et al. Compressibility and thermal expansion of hydrous ringwoodite with 2.5(3) wt\% $\mathrm{H}_{2} \mathrm{O}$. Am. Mineral. 97, 573-582 (2012).

40. Chang, Y. Y. et al. Comparative compressibility of hydrous wadsleyite and ringwoodite: Effect of $\mathrm{H}_{2} \mathrm{O}$ and implications for detecting water in the transition zone. J. Geophys. Res. 120, 8259-8280 (2015).

41. Jacobsen, S. D. et al. Effects of hydration on the elastic properties of olivine. Geophys. Res. Lett. 35, L14303 (2008)

42. Liu, L. et al. Elastic properties of hydrous forsterites under high pressure: First-principle calculations. Phys. Earth Planet. Inter. 176, $89-97(2009)$

43. Okuchi, T. et al. Synthesis of large and homogeneous single crystals of water-bearing minerals by slow cooling at deep-mantle pressures. Am. Mineral. 100, 1483-1492 (2015).

44. Smyth, J. R. et al. Crystal structure of monoclinic hydrous wadsleyite $\left[\beta-(\mathrm{Mg}, \mathrm{Fe})_{2} \mathrm{SiO}_{4}\right]$. Am. Mineral. 82, 270-275 (1997).

45. Ye, Y., Smyth, J. R., Hushur, A., Manghnani, M. H., Lonappan, D., Dera, P. \& Frost, D. J. Crystal structure of hydrous wadsleyite with $2.8 \% \mathrm{H}_{2} \mathrm{O}$ and compressibility to $60 \mathrm{GPa}$. Am. Mineral. 95, 1765-1772 (2010).

46. Artioli, G., Rinaldi, R., Wilson, C. C. \& Zanazzi, P. F. Single-crystal pulsed-neutron diffraction of a highly hydrous beryl. Acta Cryst. B 51, 733-737 (1995).

47. Gatta, G. D., McIntyre, G. J., Sassi, R., Rotiroti, N. \& Pavese, A. Hydrogen-bond and cation partitioning in muscovite: A singlecrystal neutron-diffraction study at 295 and 20 K. Am. Mineral. 96, 34-41 (2011).

48. Larson, A.C. \& Von Dreele, R.B. General structure analysis system (GSAS). Los Alamos National Laboratory Report LAUR 86, 748 (2004).

49. Larson, A.C. Inclusion of secondary extinction in least-squares calculations. Acta Cryst. 23, 664 (1967).

50. Jorgensen, M. R. V. et al. Accurate atomic displacement parameters from time-of-flight neutron-diffraction data at TOPAZ. Acta Cryst. A70, 679-681 (2014).

51. Momma, K. \& Izumi, F. VESTA3 for three-dimensional visualization of crystal, volumetric and morphology data. J. Appl. Cryst. 44, $1272-1276(2011)$.

\section{Acknowledgements}

We thank C. Oka and S. Yamashita for technical support during high-pressure synthesis and FTIR measurement, respectively. Part of the research conducted at Oak Ridge National Laboratory's Spallation Neutron Source was sponsored by the Scientific User Facilities Division, Office of Basic Energy Sciences, U. S. Department of Energy. This work was supported by JSPS KAKENHI Grant Numbers 26287135, 15J03633 and 15K13593.

\section{Author Contributions}

T.O. designed the research and N.P. synthesised the sample crystals and analysed the neutron diffraction datasets. All authors contributed to the neutron diffraction measurements. N.P. and T.O. wrote the paper. All authors were involved in reviewing the manuscript. 


\section{Additional Information}

Supplementary information accompanies this paper at http://www.nature.com/srep

Competing financial interests: The authors declare no competing financial interests.

How to cite this article: Purevjav, N. et al. Quantitative analysis of hydrogen sites and occupancy in deep mantle hydrous wadsleyite using single crystal neutron diffraction. Sci. Rep. 6, 34988; doi: 10.1038/srep34988 (2016).

(c) (i) This work is licensed under a Creative Commons Attribution 4.0 International License. The images or other third party material in this article are included in the article's Creative Commons license, unless indicated otherwise in the credit line; if the material is not included under the Creative Commons license, users will need to obtain permission from the license holder to reproduce the material. To view a copy of this license, visit http://creativecommons.org/licenses/by/4.0/

(C) The Author(s) 2016 